\title{
ИЗУЧЕНИЕ ФЕНОЛЬНЫХ СОЕДИНЕНИЙ НАДЗЕМНОЙ ЧАСТИ ХАТЬМЫ ТЮРИНГЕНСКОЙ, ПРОИЗРАСТАЮЩЕЙ НА ТЕРРИТОРИИ АЛТАЙСКОГО
}

\section{КРАЯ}

(C) Л.М. Федосеева, О.А. Мызникова ${ }^{*}$, Л.Е. Кудрикова

\author{
Алтайский государственный медицинский университет, пр. Ленина, 40, \\ Барнаул, 656054 (Россия), e-mail: olga_myznikova@mail.ru
}

Хатьма тюрингенская (Lavatera thuringiaca L.) семейства мальвовые (Malvaceae) содержит богатый комплекс биологически активных соединений и широко используется в народной медицине как противовоспалительное, обволакивающее, отхаркивающее средство. Целью настоящих исследований является изучение фенольных соединений надземной части хатьмы тюрингенской, произрастающей на территории Алтайского края. Для реализации цели необходимо решить следующие задачи: проведение качественных реакций на флавоноиды, разделение и идентификация фенольных соединений с помощью методов тонкослойной и высокоэффективной жидкостной хроматографии.

Результаты качественных реакций позволили предположить наличие в сырье флавоноидов групп флавонола, флавона, флаванона. С помощью метода тонкослойной хроматографии в системе этилацетат - уксусная кислота - вода $(70: 10: 20)$ обнаружены флавоноиды групп флавона и флавонола. Затем получали спиртовое извлечение и проводили разделение на фракции: эфирную, этилацетатную и бутанольную. Методом высокоэффективной жидкостной хроматографии в эфирной фракции идентифицировали кофейную кислоту, производные кумаровой и феруловой кислот, флавоноиды группы флавона, триметоксифлавона, изофлавона, производное халкона; в этилацетатной - кофейную кислоту, производные галловой и феруловой кислот, флавоноиды группы флавона и триметоксифлавона; в бутанольной флавоноид группы флавона, производные катехина и апигенина.

Исследования направлены на изучение возможности применения надземной части хатьмы тюрингенской в медицине. Планируется разработка нормативной документации на лекарственное сырье.

Ключевые слова: Lavatera thuringiaca L., флавоноиды, фенольные соединения.

\section{Введение}

Многолетнее травянистое растение хатьма тюрингенская (Lavatera thuringiaca L.) семейства мальвовые (Malvaceae) представляет интерес как доступный источник комплекса биологически активных соединений (БАС): полисахариды, флавоноиды, фенолокислоты, дубильные вещества, кумарины [1, 2]. Поскольку в литературе отсутствует информация о химическом составе надземной части хатьмы тюрингенской, произрастающей на территории Алтайского края, изучение фенольных соединений данного сырья представляется актуальной проблемой и является целью настоящей работы.

\section{Экспериментальная часть}

Для исследования использовали надземную часть хатьмы тюрингенской, заготовленную в период цветения (июль) на территории Бийского района Алтайского края в 2015 г.

Для проведения качественных реакций на флавоноиды из надземной части хатьмы тюрингенской

Федосеева Людмила Михайловна - доктор

фармацевтических наук, профессор,

e-mail: ludmila@agmu.ru

Мызникова Ольга Александровна - аспирант, e-mail: olga myznikova@mail.ru

Кудрикова Людмила Евдокимовна - кандидат фармацевтических наук, доцент кафедры фармации, e-mail: lek212@mail.ru было получено извлечение с использованием 70\% этанола (соотношение сырье - экстрагент $1: 10$ ). Проводили следующие испытания: цианидиновая проба, борно-лимонная реакция, реакция с аммиака раствором $10 \%$; свинца ацетата основного раствором $2 \%$; ванилина раствором $1 \%$ [3].

\footnotetext{
* Автор, с которым следует вести переписку.
} 
Исследование качественного состава и идентификацию флавоноидов осуществляли методом тонкослойной хроматографии (ТCX) на пластинках Sorbfil в следующих системах растворителей: спирт $\mu$-бутиловый - уксусная кислота ледяная - вода $(4: 1: 1)$ и $(4: 1: 2)$, хлороформ - уксусная кислота ледяная - вода (10: $4: 1)$, хлороформ - уксусная кислота ледяная $(5: 2)$, ацетон - эфир петролейный (10:45), этилацетат - уксусная кислота - вода (70 : $10: 20)$, уксусная кислота 15\%. В качестве свидетелей использовали стандартные образцы флавоноидов из группы флавонола (рутин, каталожный номер R5143; кверцетин, каталожный номер Q4951; кемпферол, каталожный номер К0133) и флавона (апигенин, каталожный номер A3145; лютеолин, каталожный номер L9283), приобретенные в компании ООО «Сигма-Алдрич Рус». Детектирование пятен веществ на хроматограммах проводили путем обработки пластинок алюминия хлорида раствором спиртовым 5\%, затем хроматограммы просматривали в УФ-свете (254 нм, 365 нм).

С целью исследования состава флавоноидов далее проводили разделение спиртового извлечения на фракции (эфирную, этилацетатную и бутанольную) [4]. Анализ фракций методом высокоэффективной жидкостной хроматографии (ВЭЖХ) осуществляли на микроколоночном жидкостном хроматографе «МилиХром А-02» с УФ-детектором. Условия ВЭЖХ: хроматографическая колонка 2,0×75 мм; сорбент NucleoSIL-120-5-C18 с размером частиц 5 мкм; элюент A - раствор кислоты трифторуксусной водный 0,01\%, элюент Б - ацетонитрил. Скорость подачи элюента - 100 мкл/мин, объем пробы - 2 мкл, температура колонки $35{ }^{\circ} \mathrm{C}$; градиент 5-55\% элюента Б за 30 мин. Детектирование веществ проводили при длинах волн $220,254,268,300,324,360$ нм. Соединения идентифицировали по временам удерживания $(\tau)$ и спектральным характеристикам $\left(\lambda_{\max }\right)$ путем сравнения с аналогичными показателями стандартных образцов и литературными данными $[5,6]$.

\section{Обсуждение результатов}

Для получения предварительной информации о составе флавоноидов надземной части хатьмы тюрингенской проводили качественные реакции. Получали извлечение надземной части хатьмы тюрингенской с использованием 70\% этанола (соотношение сырье - экстрагент $1: 10$ ). Обнаружение флавоноидов проводили по общепринятым методикам [3]. Положительные результаты реакций позволили предположить, что надземная часть хатьмы тюрингенской содержит флавоноиды групп флавонола, флавона, флаванона (табл. 1).

Для разделения и идентификации соединений использовали метод ТСХ. В ходе исследования установили, что оптимальными разделяющими свойствами обладает система этилацетат - уксусная кислота вода $(70: 10: 20)$. После хроматографирования спиртового извлечения и обработки пластинки алюминия хлорида раствором спиртовым 5\% обнаружили два пятна желтого цвета $\left(\mathrm{R}_{\mathrm{fl}}=0,14 ; \mathrm{R}_{\mathrm{f} 2}=0,89\right)$ с желтозеленой флюоресценцией в УФ-свете, что характерно для флавоноидов групп флавона и флавонола. Идентифицировать индивидуальные соединения метод ТСХ не позволил.

Для разделения флавоноидов на фракции проводили последовательную обработку спиртового извлечения эфиром (агликоны), этилацетатом (монозиды), спиртом $н$-бутиловым. Полученные фракции исследовали методом ВЭЖХ. Соединения идентифицировали по временам удерживания и спектральным характеристикам в сравнении с аналогичными показателями стандартных образцов.

Таблица 1. Результаты качественных реакций на флавоноиды надземной части хатьмы тюрингенской

\begin{tabular}{|c|c|c|}
\hline Реактив (реакция) & Группы флавоноидов & Результат реакции \\
\hline Цианидиновая проба & $\begin{array}{l}\text { Флавонолы, флавоны, флаваноны } \\
\text { (оранжево-красное окрашивание) }\end{array}$ & Оранжево-красное окрашивание \\
\hline Борно-лимонная реакция & $\begin{array}{l}\text { 5-оксифлавоны, 5-оксифлавонолы, (желтое } \\
\text { окрашивание, желто-зеленая флюоресценция) }\end{array}$ & $\begin{array}{l}\text { Желтое окрашивание, желто- } \\
\text { зеленая флюоресценция }\end{array}$ \\
\hline Аммиака раствор $10 \%$ & $\begin{array}{c}\text { Халконы, ауроны (красное окрашивание); фла- } \\
\text { вонолы, флавоны, флаваноны, флаванонолы } \\
\text { (желтое окрашивание, переходящее при нагре- } \\
\text { вании в оранжевое); антоцианы } \\
\text { (синее окрашивание) }\end{array}$ & Желтое окрашивание \\
\hline $\begin{array}{l}\text { Свинца (II) ацетата основного } \\
\text { раствор }\end{array}$ & $\begin{array}{c}\text { Флавоны, халконы, ауроны (желтый осадок); } \\
\text { антоцианы (красный или синий осадок) }\end{array}$ & Образование желтого осадка \\
\hline Ванилина раствор 1\% & Катехины (малиново-красное окрашивание) & Коричневое окрашивание \\
\hline
\end{tabular}


В ходе исследования на хроматограммах эфирной и этилацетатной фракций появилось по семь пиков, бутанольной - восемь пиков (табл. 2).

Соединения эфирной фракции: пик 1 ( $\tau=11,9$ мин; $\lambda_{\max }=216 ; 235 п л ; 300 п л ; 325$ нм) - кофейная кислота, пик 2 ( $\tau=14,4$ мин; $\lambda_{\max }=200 ; 225 ; 310$ нм) - производное кумаровой кислоты, пик 3 ( $\tau=15,5$ мин; $\lambda_{\max }=218 ; 235 ; 300 п л ; 325$ нм) - производное феруловой кислоты, пик 4 ( $\tau=20,8$ мин; $\lambda_{\max }=200 ; 220 п л$; $267 ; 320$ нм) - агликон триметоксифлавона, пик $5\left(\tau=21,3\right.$ мин; $\lambda_{\max }=200 ; 264 ; 320$ нм $)$ - агликон флавона, пик 6 ( $\tau=27,2$ мин; $\lambda_{\max }=268$ нм; 310пл) - производное изофлавона, пик 7 ( $\tau=29,2$ мин; $\lambda_{\max }=222 ; 318$ нм - производные халкона. Наиболее выраженные пики образуют производные кумаровой и феруловой кислот, агликон триметоксифлавона, производное халкона (рис. 1).

Соединения этилацетатной фракции: пик 1 ( $\tau=11,9$ мин; $\lambda_{\max }=216 ; 235 п$; 300пл; 325 нм) - кофейная кислота, пик 2 ( $\tau=14,5$ мин; $\lambda_{\max }=218 ; 280$ нм) - производное галловой кислоты, пик 3 ( $\tau=15,5$ мин; $\lambda_{\max }=218 ; 235 ; 300 п л ; 325$ нм) - производное феруловой кислоты, пик 4 ( $\tau=16,5$ мин; $\lambda_{\max }=200 ; 267$; 350 нм) - монозид флавоноида группы флавона; пик 5 ( $\tau=18,2$ мин; $\lambda_{\max }=200 ; 220 п л ; 270 ; 350$ нм) - монозид флавоноида группы флавона; пик $6\left(\tau=20,8\right.$ мин; $\lambda_{\max }=200 ; 220 п л ; 267 ; 320$ нм) - агликон триметоксифлавона; пик 7 ( $\tau=21,3$ мин; $\lambda_{\max }=200 ; 267 ; 320$ нм) - агликон флавона. Наиболее выраженный пик образует агликон триметоксифлавона (рис. 2).

Таблица 2. Результаты исследований состава фенольных соединений надземной части хатьмы тюрингенской методом ВЭЖХ

\begin{tabular}{|c|c|c|c|}
\hline $\begin{array}{l}\text { Номер } \\
\text { пика }\end{array}$ & $\begin{array}{c}\text { Время удержива- } \\
\text { ния, мин }\end{array}$ & Максимум поглощения, нм & Соединение \\
\hline \multicolumn{4}{|c|}{ Эфирная фракция } \\
\hline 1 & 11,9 & 216; 235пл; 300пл; 325 & Кофейная кислота \\
\hline 2 & 14,4 & $200 ; 225 ; 310$ & Производное кумаровой кислоты \\
\hline 3 & 15,5 & 218; 235; 300пл; 325 & Производное феруловой кислоты \\
\hline 4 & 20,8 & 200; 220пл; 267; 320 & Агликон триметоксифлавона \\
\hline 5 & 21,3 & $200 ; 264 ; 320$ & Агликон флавона \\
\hline 6 & 27,2 & 268, 310пл & Производное изофлавона \\
\hline 7 & 29,2 & 222,318 & Производное халкона \\
\hline \multicolumn{4}{|c|}{ Этилацетатная фракция } \\
\hline 1 & 11,9 & 216; 235пл; 300пл; 325 & Кофейная кислота \\
\hline 2 & 14,5 & $218 ; 280$ & Производное галловой кислоты \\
\hline 3 & 15,5 & 218; 235; 300пл; 325 & Производное феруловой кислоты \\
\hline 4 & 16,5 & $200 ; 267 ; 350$ & \\
\hline 5 & 18,2 & 200; 220пл; 270; 350 & Флавоноиды группы флавона \\
\hline 6 & 20,8 & 200; 220пл; 267; 320 & Агликон триметоксифлавона \\
\hline 7 & 21,3 & $200 ; 267 ; 320$ & Агликон флавона \\
\hline \multicolumn{4}{|c|}{ Бутанольная фракция } \\
\hline 1 & 11,5 & $205 ; 279$ & Производное катехина \\
\hline 2 & 12,4 & 200; 220пл; 270; 335 & Производное апигенина \\
\hline 3 & 13,0 & $200 ; 269$ & \\
\hline 4 & 13,5 & $205 ; 275$ & \\
\hline 5 & 17,3 & $203 ; 272$ & Производные катехина \\
\hline 6 & 17,6 & $203 ; 276$ & \\
\hline 7 & 20,5 & 200пл; 215пл; 268; 315 & Флавоноид группы флавона \\
\hline 8 & 21,1 & $200 ; 270$ & Производное катехина \\
\hline \multicolumn{4}{|c|}{ Стандартные образцы } \\
\hline 1 & 12,0 & 218; 235пл; 300пл; 323 & Кофейная кислота \\
\hline 2 & 14,9 & $209 ; 220 ; 286$ & Кумаровая кислота \\
\hline 3 & 15,9 & 215; 235; 300пл; 323 & Феруловая кислота \\
\hline 4 & 21,0 & $265 ; 325$ & 5, 7, 4'-Триметоксифлавон \\
\hline 5 & 19,3 & 250; 294; 307пл & Флавон \\
\hline 6 & 27,5 & 268, 307пл & Изофлавон \\
\hline 7 & 29,9 & $230 ; 312$ & Халкон \\
\hline 8 & 14,6 & 218,280 & Китайский танин (производное галловой кислоты) \\
\hline 9 & 20,3 & $213 ; 279$ & Катехин \\
\hline 10 & 24,2 & 196; 210пл; 268; 337 & Апигенин \\
\hline
\end{tabular}




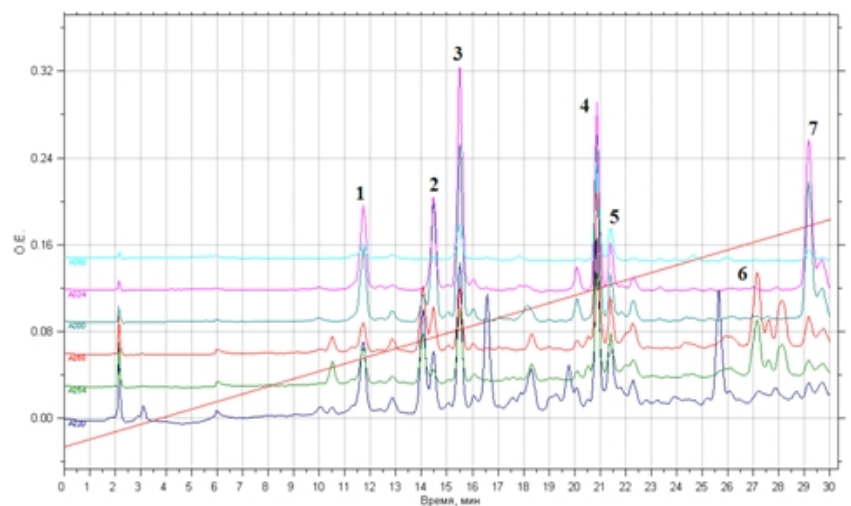

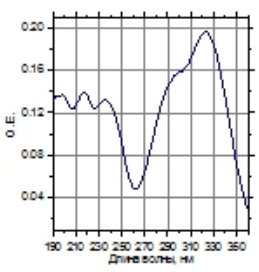

3

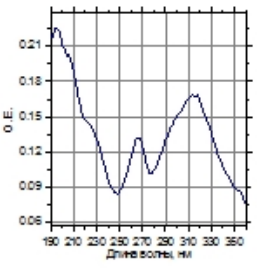

4

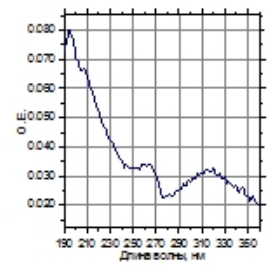

5

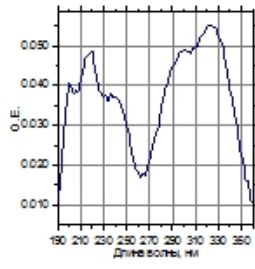

1

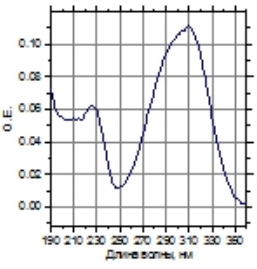

2

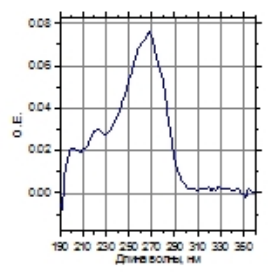

6

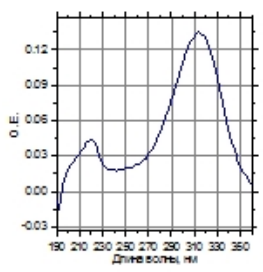

7

Рис. 1. Хроматограмма эфирной фракции спиртового извлечения надземной части хатьмы тюрингенской и спектры поглощения соединений: 1 - кофейная кислота ( $\tau=11,9$ мин), 2 - производное кумаровой кислоты ( $\tau=14,4$ мин), 3 - производное феруловой кислоты ( $\tau=15,5$ мин), 4 - агликон триметоксифлавона ( $\tau=20,8$ мин), 5 - агликон флавона $(\tau=21,3$ мин), 6 - производное изофлавона $(\tau=27,2$ мин), $7-$ производное халкона $(\tau=29,2$ мин $)$

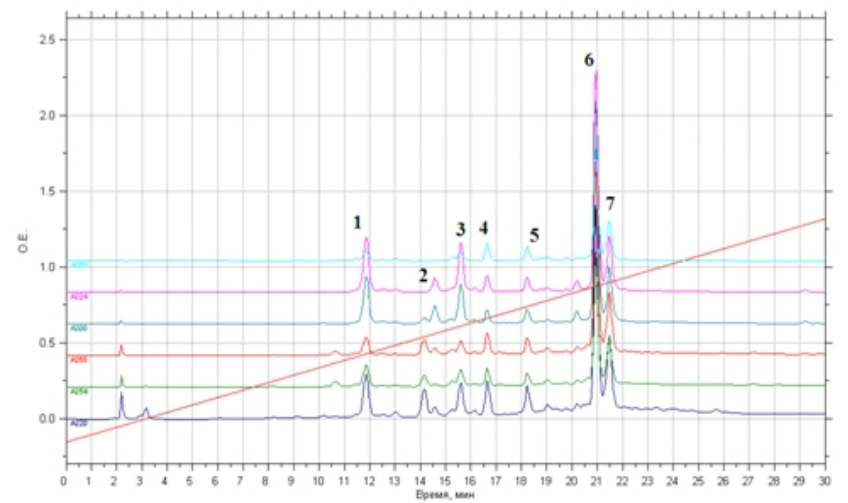

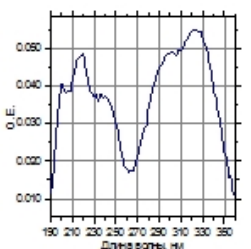

1

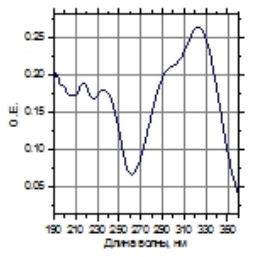

3

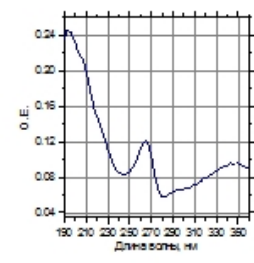

4

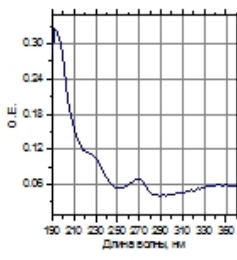

5

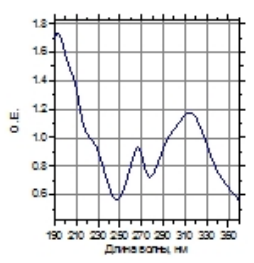

6

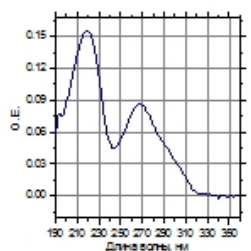

2

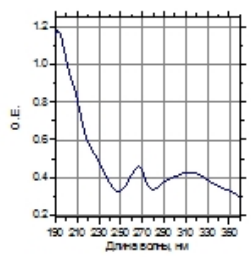

7

Рис. 2. Хроматограмма этилацетатной фракции спиртового извлечения надземной части хатьмы тюрингенской и спектры поглощения соединений: 1 - кофейная кислота $(\tau=11,9$ мин), 2 - производное галловой кислоты ( $\tau=14,5$ мин), 3 - производное феруловой кислоты $(\tau=15,5$ мин $), 4-$ флавоноид группы флавона $(\tau=16,5$ мин $), 5$ - флавоноид группы флавона $(\tau=18,2$ мин), 6 - агликон триметоксифлавона $(\tau=20,8$ мин $), 7$ - агликон флавона $(\tau=21,3$ мин)

В эфирной и этилацетатной фракциях обнаружены соединения с временами удерживания 20,8 мин и 21,3 мин и спектрами поглощения с $\lambda_{\max }=200 ; 220 п л ; 267 ; 320$ нм и $\lambda_{\max }=200 ; 267 ; 320$ нм соответственно. По данным характеристикам вещества, возможно, являются агликонами флавоноидов. 
Соединения бутанольной фракции: пик 1 ( $\tau=11,5$ мин; $\lambda_{\max }=205 ; 279$ нм), пик 3 ( $\tau=13,0$ мин; $\lambda_{\max }=200 ; 269$ нм), пик $4\left(\tau=13,5\right.$ мин; $\lambda_{\max }=205 ; 275$ нм), пик $5\left(\tau=17,3\right.$ мин; $\lambda_{\max }=203 ; 272$ нм $)$, пик 6 $\left(\tau=17,6\right.$ мин; $\lambda_{\max }=203 ; 276$ нм), пик $8\left(\tau=21,1\right.$ мин; $\lambda_{\max }=200 ; 270$ нм $)$ - производные катехина; пик 2 $\left(\tau=12,4\right.$ мин; $\lambda_{\max }=200 ; 220 п л ; 270 ; 335$ нм $)$ - производное апигенина; пик $7\left(\tau=20,5\right.$ мин; $\lambda_{\max }=200 п л$; 215пл; 268; 315 нм) - флавоноид группы флавона (рис. 3).

Нами установлен состав комплекса фенольных соединений надземной части хатьмы тюрингенской, включающий фенолокислоты, производные флавона, изофлавона, катехина, халкона, галловой кислоты.

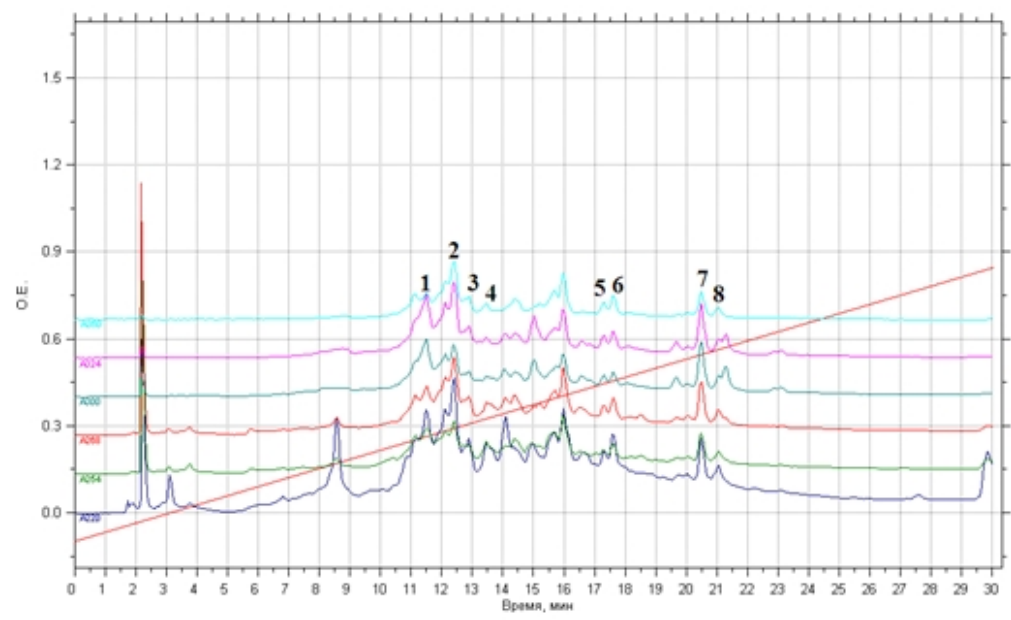

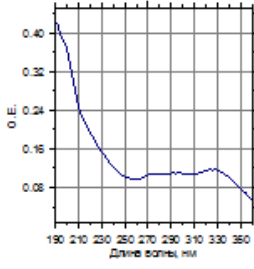

1

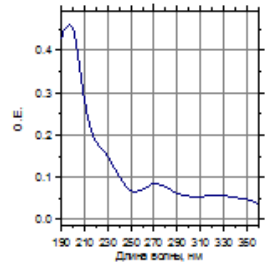

5

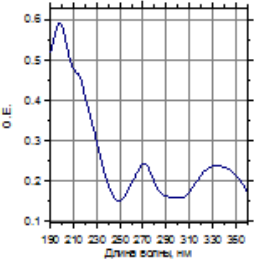

2

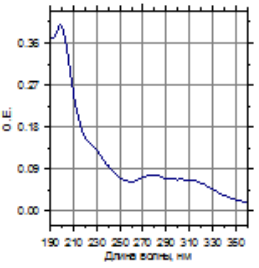

6

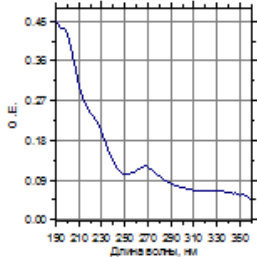

3

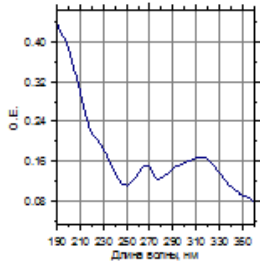

7

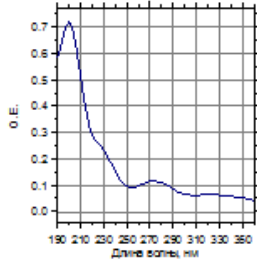

4

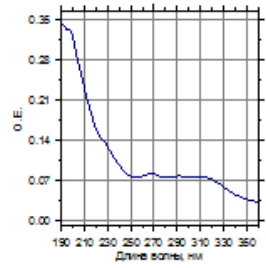

8

Рис. 3. Хроматограмма бутанольной фракции спиртового извлечения надземной части хатьмы тюрингенской и спектры поглощения соединений: 1 - производное катехина $(\tau=11,5$ мин $), 2-$ производное апигенина ( $\tau=12,4$ мин), 3 - производное катехина $(\tau=13,0$ мин), 4 - производное катехина $(\tau=13,5$ мин), 5 - производное катехина $(\tau=17,3$ мин), 6 - производное катехина $(\tau=17,6$ мин $), 7-$ флавоноид группы флавона $(\tau=20,5$ мин $), 8-$ производное катехина $(\tau=21,1$ мин)

\section{Выводы}

В результате исследования на основании качественных реакций, ТСХ и ВЭЖХ установлено, что надземная часть хатьмы тюрингенской, произрастающая на территории Алтайского края, содержит оксикоричные кислоты (кофейная кислота, производные кумаровой и феруловой кислот), флавоноиды группы флавона, изофлавона, производное галловой кислоты, производное халкона, производные катехина.

Дальнейшие исследования будут направлены на количественное определение фенольных соединений надземной части хатьмы тюрингенской физико-химическими методами. 


\section{Список литературы}

1. Лавренов В.К., Лавренова Г.В. Современная энциклопедия лекарственных растений. М., 2007. 272 с.

2. Махлаюк В.П. Лекарственные растения в народной медицине. Саратов, 1993. 544 с.

3. Ладыгина Е.Я., Сафронич Л.Н., Отряшенкова В.Э. и др. Химический анализ лекарственных растений: учеб. пособие для фармац. вузов. М., 1983. 176 с.

4. Федосеева Л.М., Кирьякова В.О. Изучение некоторых фенольных соединений крапивы коноплевой травы, произрастающей на территории Алтайского края // Химия растительного сырья. 2012. № 2. С. 133-138.

5. Mabry T.J., Markham K.R., Thomas M.B. The Systematic Identification of Flavonoids. Berlin; Heidelberg; NewYork, 1970. $354 \mathrm{p}$.

6. Wagner H., Bauer R., Melchart D., Xiao P.-G., Staudinger A. Chromatographic Fingerprint Analysis of Herbal Medicines. New-York, 2011. 1012 p.

Поступило в редакичю 6 октября 2016 г.

После переработки 16 ноября 2016 г.

Fedoseeva L.M., Myznikova O.A.*, Kudrikova L.E. STUDY OF PHENOLIC COMPOUNDS IN ABOVEGROUND PART OF LAVATERA THURINGIACA, GROWING IN THE ALTAI KRAI

Altai State Medical University, pr. Lenina, 40, Barnaul, 656054 (Russia), e-mail: olga_myznikova@mail.ru

Lavatera thuringiaca L. family Malvaceae (Malvaceae) contains a rich complex of biologically active compounds and is widely used in folk medicine as an anti-inflammatory, enveloping, expectorant agent. The goal of this research is to study of phenolic compounds in aboveground part of Lavatera thuringiaca, growing in the Altai Region. To achieve the goal needs to solve the following problem: conducting qualitative reactions to flavonoids, separation and identification of phenolic compounds by TLC and HPLC.

The results of qualitative reactions allowed to sugges the presence in the raw material of flavonoids groups flavonol, flavone, flavanone. Using the method of thin layer chromatography in the system ethyl acetate - acetic acid - water (70:10:20) detected flavonoids flavone and flavonol groups. Then prepared ethanolic extraction and separation was divided into fractions: ether, ethylacetate and butanolic. By HPLC in the ester fraction were identified caffeic acid, coumaric derivatives and ferulic acid, flavonoids of flavone, trimethoxyflavone, isoflavone groups, chalcone derivative; in ethyl acetate fraction - caffeic acid, gallic derivatives and ferulic acids, flavonoids of flavone, trimethoxyflavone groups; in butanol fraction - flavonoid of group flavone, apigenin and catechol derivatives.

The research aimed at studying the possibility of applying the aboveground part of the Lavatera thuringiaca in medicine. It is planned to develop standard documentation on medicinal plant raw material.

Keywords: Lavatera thuringiaca L., flavonoids, phenolic compounds.

\section{References}

1. Lavrenov V.K., Lavrenova G.V. Sovremennaia entsiklopediia lekarstvennykh rastenii. [The modern encyclopedia of medicinal plants]. Moscow, 2007, 272 p. (in Russ.).

2. Makhlaiuk V.P. Lekarstvennye rasteniia v narodnoi meditsine. [Medicinal plants in folk medicine]. Saratov, 1993, 544 p. (in Russ.).

3. Ladygina E.Ia., Safronich L.N., Otriashenkova V.E. i dr. Khimicheskii analiz lekarstvennykh rastenii: ucheb. posobie dlia farmats. vuzov. [Chemical analysis of medicinal plants: a textbook for pharmaceutical universities]. Moscow, 1983, 176 p. (in Russ.).

4. Fedoseeva L.M., Kir'iakova V.O. Khimiia rastitel'nogo syr'ia, 2012, no. 2, pp. 133-138. (in Russ.).

5. Mabry T.J., Markham K.R., Thomas M.B. The Systematic Identification of Flavonoids, Berlin, Heidelberg, NewYork, 1970, $354 \mathrm{p}$.

6. Wagner H., Bauer R., Melchart D., Xiao P.-G., Staudinger A. Chromatographic Fingerprint Analysis of Herbal Medicines, New-York, 2011, $1012 \mathrm{p}$.

Received October 6, 2016

Revised November 16, 2016

\footnotetext{
* Corresponding author.
} 